\title{
Wild-Type Transthyretin Amyloidosis in Female Patients - Consideration of Sex Differences -
}

\author{
Yuri Ochi, MD; Toru Kubo, MD; Yuichi Baba, MD; Kenta Sugiura, MD; \\ Motoko Ueda, MD; Kazuya Miyagawa, MD; Tatsuya Noguchi, MD; Takayoshi Hirota, MD; \\ Tomoyuki Hamada, MD; Naohito Yamasaki, MD; Hiroaki Kitaoka, MD
}

Background: With recent advances in non-invasive diagnostic tools, some studies indicate that wild-type transthyretin amyloidosis (ATTRwt) may be more common in females than previously reported. However, the clinical characteristics of female ATTRwt patients have not been determined.

\begin{abstract}
Methods and Results: Of the 78 consecutive patients with ATTRwt in our cohort, 14 (17.9\%) were female. Compared with male patients, female ATTRwt patients had smaller left ventricular (LV) wall thicknesses (ventricular septum thickness $12.9 \mathrm{vs} .14 .2 \mathrm{~mm}$ $[P=0.081]$; posterior wall thickness 12.7 vs. $13.6 \mathrm{~mm}[\mathrm{P}=0.035]$ ) and a higher LV ejection fraction (EF; mean $[ \pm S D] 58.4 \pm 8.9 \%$ vs. $48.9 \pm 11.8 \% ; P=0.006)$. However, the severity of heart failure $(\mathrm{HF})$, as assessed by HF stage, New York Heart Association functional class and B-type natriuretic peptide concentrations, did not differ between female and male patients. Moreover, LV mass index and relative wall thickness were increased and the stroke volume index was reduced in both female and male patients. In organ biopsies, female patients had a higher sensitivity to transthyretin deposition from abdominal fat than male patients (positive abdominal fat biopsy $80.0 \%$ vs. $26.5 \%$; $P=0.016)$.
\end{abstract}

Conclusions: This study suggests that a relatively large proportion of elderly females have ATTRwt. Female ATTRwt patients had HF symptoms even at the stage of mild LV hypertrophy and preserved EF. Abdominal fat biopsy may be useful to diagnose ATTRwt, especially in female patients with HF.

Key Words: Cardiac amyloidosis; Female patient; Sex differences; Wild-type transthyretin amyloidosis

W ild-type transthyretin amyloidosis (ATTRwt), which has been referred to as senile or agerelated amyloidosis, is an underappreciated cause of heart failure (HF) resulting from the deposition of wild-type transthyretin (TTR) that forms amyloid fibrils. Although it has been traditionally perceived as a rare disease and is often underdiagnosed, ${ }^{1,2}$ recent evidence suggests that ATTRwt is probably more common than has been thought, especially in elderly patients with HF.,4 Oral tafamidis has been approved in Japan for the treatment of patients with ATTRwt since 2019.5-7 In this new era for patients with ATTRwt, accurate diagnosis is essential for appropriate management.

Previous studies have indicated that ATTRwt has a very strong male predominance; ${ }^{2,8-10}$ therefore, it has been thought that ATTRwt is very rare in female patients. However, these data were based on studies in patients with ATTRwt diagnosed using a conventional diagnostic procedure with biopsy-proven transthyretin amyloid deposi- tion. Recently, with the development of new diagnostic strategies using non-invasive tools, some studies have indicated that ATTRwt may be more common in females than previously reported. ${ }^{11,12}$ Nevertheless, there have been very few reports about the clinical characteristics of female ATTRwt patients, $11,13,14$ and there has been no report on sex differences in Japanese patients with ATTRwt. Here, we discuss sex differences in patients with ATTRwt in a cohort of Japanese patients.

\section{Methods}

\section{Patient Population and Clinical Definitions}

Seventy-eight consecutive patients with ATTRwt who were diagnosed as having cardiac amyloidosis (CA) at Kochi Medical School Hospital between April 2012 and October 2020 were included in this study.

In this study, all patients underwent technetium-99m pyrophosphate ( $99 \mathrm{~m} \mathrm{Tc}-\mathrm{PYP})$ scintigraphy. The diagnosis of

\footnotetext{
Received May 30, 2021; accepted May 31, 2021; J-STAGE Advance Publication released online June 29, 2021 Time for primary review: 1 day

Department of Cardiology and Geriatrics, Kochi Medical School, Kochi University, Nankoku, Japan

H.K. is a member of Circulation Reports' Editorial Team.

Mailing address: Toru Kubo, MD, Department of Cardiology and Geriatrics, Kochi Medical School, Kochi University, Oko-cho, Nankoku 783-8505, Japan. E-mail: jm-kubotoru@kochi-u.ac.jp

All rights are reserved to the Japanese Circulation Society. For permissions, please e-mail: cr@j-circ.or.jp

ISSN-2434-0790
} 


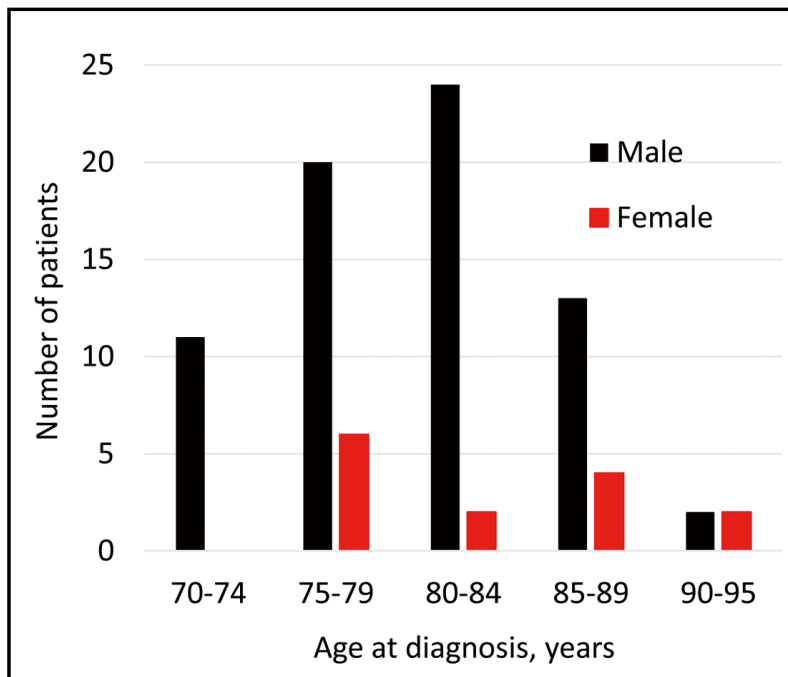

Figure. Proportion of patients with wild-type transthyretin amyloidosis (ATTRwt) by sex according to age.

transthyretin amyloidosis (ATTR) was established by biopsy-proven TTR in at least one involved organ and/or positive uptake on ${ }^{99 \mathrm{~m} T c-P Y P}$ scintigraphy with a normal free light chain ratio and serum immunofixation according to the Japanese Circulation Society 2020 guidelines. ${ }^{7}$ The subtype of ATTRwt was established by the absence of identifiable mutations following genetic testing and/or apparent signs and a family history indicative of variant ATTR (ATTRv). All patients had CA based on the following criteria: (1) endomyocardial biopsy (EMB)-proven TTR amyloid deposition; and (2) in the absence of an EMB, biopsy-proven TTR amyloid deposits in $\geq 1$ extracardiac organ with echocardiographically defined evidence of amyloid cardiomyopathy ${ }^{15}$ and/or positive uptake on 99m Tc-PYP scintigraphy. ${ }^{16,17}$

This investigation was performed in accordance with the tenets of the Declaration of Helsinki. This retrospective study was approved by the Ethics Committee on Medical Research of Kochi Medical School.

\section{Clinical Evaluation}

A retrospective review was conducted of the medical records of all patients at the time of ATTRwt diagnosis. We determined the proportion of patients with newly diagnosed ATTRwt in the Kochi Medical School Hospital and assessed differences between male and female patients in terms of clinical manifestations, imaging parameters, and tissue biopsies.

\section{Clinical Characteristics}

HF was categorized into subtypes $\mathrm{A}, \mathrm{B}, \mathrm{C}$, and $\mathrm{D}$ according to the American College of Cardiology Foundation/American Heart Association guidelines, ${ }^{18}$ and the severity of HF symptoms was assessed by New York Heart Association (NYHA) functional class. Plasma B-type natriuretic peptide (BNP) was measured using an enzyme immunoassay (TOSOH, Tokyo, Japan). Serum high-sensitivity cardiac troponin T (hs-cTnT) was measured using the Elecsys troponin T high sensitivity immunoassay (Roche Diagnostics,

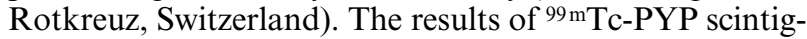

raphy were analyzed according to a previously reported grading system for planar images: scans were defined as positive when Grade 2 or $3{ }^{99 \mathrm{~m} T c-P Y P}$ uptake was evident in the left ventricle. ${ }^{16,17}$

\section{Electrocardiography and Echocardiography}

Electrocardiograms (ECG) were reviewed for rhythm abnormalities, QRS duration, the presence of low-voltage and poor precordial $\mathrm{R}$ wave progression, ${ }^{\mathbf{1 9}}$ and arrhythmia.

Data for echocardiographic standard 2-dimensional measurements were obtained as recommended by the current guidelines. ${ }^{20}$ Left ventricular (LV) ejection fraction (EF) was calculated using the Teichholz method or modified Simpson's method. Stroke volume (SV) was calculated from Doppler measurements of LV outflow tract (LVOT) diameter and the flow time-velocity integral (VTI) as LVOT area $\times$ LVOT VTI and was indexed to body surface area (BSA) to obtain the SV index (SVI). LV mass index (LVMI) was calculated by Devereux's formula using diastolic measurements of LV end-diastolic diameter (LVEDD) and interventricular septal (IVS) and posterior wall (PW) thicknesses. Relative wall thickness (RWT) was calculated as $(2 \times \mathrm{PW}$ thickness at end diastole)/LVEDD. Left atrium (LA) volume was measured using the biplane method of disks. The LA volume index (LAVI) was calculated by dividing LA volume by BSA. Mitral peak velocity of early filling (E) was measured using the pulse wave Doppler method. Early diastolic mitral annular velocity (e') was measured using the tissue Doppler method.

\section{Organ Biopsies}

The site and yield of tissue sampling for histologic confirmation of TTR-related amyloid protein deposition were assessed. Biopsy specimens were stained with hematoxylineosin and Congo red. Immunostaining was performed using monoclonal antibodies directed against amyloid A (AA) protein and TTR amyloid protein.

\section{Statistical Analysis}

All variables were compared between male and female patients with ATTRwt. Normality of data distribution was assessed using the Shapiro-Wilk test. Categorical variables are expressed as numbers (percentages) and continuous variables are presented as the mean $\pm \mathrm{SD}$ in the case of normally distributed variables) or as the median with interquartile range (IQR) for non-normally distributed variables. To determine the significance of differences between 2 groups, unpaired t-tests or the Mann-Whitney test were used for continuous variables and the Chi-squared test was used for categorical variables.

Two-sided $\mathrm{P}<0.05$ was considered significant. Statistical analyses were performed using IBM SPSS statistics version 21.0 (IBM Corp., Armonk, NY, USA).

\section{Results}

\section{Prevalence and Clinical Characteristics of ATTRwt According to Sex}

The proportion of patients with newly diagnosed ATTRwt in Kochi Medical School Hospital according to age is shown in the Figure. The proportion of females among our ATTRwt patient cohort was 17.9\% (14 females among 78 ATTRwt patients). The age at diagnosis did not differ between female and male patients (Table 1; Figure).

Table 1 shows the main clinical characteristics of the 
Table 1. Clinical Characteristics of Patients ATTRwt at the Time of Diagnosis

\begin{tabular}{|c|c|c|c|c|}
\hline & $\begin{array}{c}\text { All patients } \\
(n=78)\end{array}$ & $\begin{array}{c}\text { Females } \\
(n=14)\end{array}$ & $\begin{array}{l}\text { Males } \\
(n=64)\end{array}$ & $P$ value \\
\hline \multicolumn{5}{|l|}{ Age (years) } \\
\hline At diagnosis & $81.3 \pm 5.2$ & $82.5 \pm 6.0$ & $80.9 \pm 4.9$ & 0.292 \\
\hline At onset of cardiac symptoms & $79.5 \pm 5.4$ & $82.0 \pm 6.6$ & $78.4 \pm 5.0$ & 0.072 \\
\hline Stage $\mathrm{C}$ or $\mathrm{D}$ heart failure at diagnosis & $60(76.9)$ & $10(71.4)$ & $50(78.1)$ & 0.328 \\
\hline NYHA functional class $\geq \mathrm{III}$ at diagnosis & $44(56.4)$ & $8(57.1)$ & $36(56.2)$ & 0.807 \\
\hline Body surface area $\left(\mathrm{m}^{2}\right)$ & $1.56 \pm 0.16$ & $1.36 \pm 0.09$ & $1.61 \pm 0.13$ & $<0.001$ \\
\hline \multicolumn{5}{|l|}{ Comorbidities } \\
\hline Hypertension or history of hypertension & $42(53.8)$ & $8(57.1)$ & $34(53.1)$ & 0.785 \\
\hline Coronary artery disease & $17(21.8)$ & $4(28.5)$ & $13(20.3)$ & 0.498 \\
\hline Aortic valve stenosis & $2(2.6)$ & 0 & $2(3.1)$ & NA \\
\hline Carpal tunnel syndrome & $34(43.4)$ & $7(50.0)$ & $27(42.2)$ & 0.593 \\
\hline Lumbar spinal canal stenosis & $22(28.2)$ & $3(21.5)$ & $19(29.7)$ & 0.786 \\
\hline \multicolumn{5}{|l|}{ Laboratory data } \\
\hline $\mathrm{BNP}(\mathrm{pg} / \mathrm{mL})$ & 288 [217-509] & 253 [166-528] & 296 [221-495] & 0.263 \\
\hline hs-cTnT (ng/mL) & $0.065[0.051-0.091]$ & $0.064[0.036-0.075]$ & $0.065[0.053-0.094]$ & 0.225 \\
\hline eGFR (mL/min/1.73 m²) & $48.9 \pm 19.7$ & $51.5 \pm 18.5$ & $48.3 \pm 20.1$ & 0.589 \\
\hline Hemoglobin (g/dL) & $12.7 \pm 1.9$ & $11.7 \pm 1.2$ & $12.9 \pm 1.9$ & 0.030 \\
\hline Serum albumin (g/dL) & $3.87 \pm 0.48$ & $3.94 \pm 0.42$ & $3.86 \pm 0.50$ & 0.842 \\
\hline Positive $99 \mathrm{mT}$-PYP scintigraphy & $74(94.9)$ & $13(92.9)$ & $61(94.9)$ & 0.821 \\
\hline
\end{tabular}

Unless indicated otherwise, data are shown as mean $\pm \mathrm{SD}$, the median [interquartile range], or as $\mathrm{n}(\%)$. ATTRwt, wild-type transthyretin amyloidosis; BNP, B-type natriuretic peptide; eGFR, estimated glomerular filtration rate; hs-cTnT, high-sensitivity cardiac troponin T; NA, not available; NYHA, New York Heart Association; $99 \mathrm{mTC}-\mathrm{PYP}$, technetium-99 m pyrophosphate.

Table 2. Electrocardiographic and Echocardiographic Findings in Patients With ATTRwt at the Time of Diagnosis

\begin{tabular}{|c|c|c|c|c|}
\hline & $\begin{array}{l}\text { All patients } \\
(\mathrm{n}=78)\end{array}$ & $\begin{array}{c}\text { Females } \\
(n=14)\end{array}$ & $\begin{array}{l}\text { Males } \\
(n=64)\end{array}$ & $P$ value \\
\hline \multicolumn{5}{|l|}{ ECG findings } \\
\hline Atrial fibrillation & $43(55.1)$ & $7(50.0)$ & $36(56.3)$ & 0.670 \\
\hline QRS duration (ms) & 116 [99-148] & 115 [89-147] & $116[101-147]$ & 0.450 \\
\hline Low voltage & $24(30.8)$ & $6(42.8)$ & $18(28.1)$ & 0.516 \\
\hline Poor precordial R wave progression & $30(38.5)$ & $5(35.7)$ & $25(39.0)$ & 0.868 \\
\hline Low-voltage and poor precordial $\mathrm{R}$ wave progression & $13(16.7)$ & $2(14.3)$ & $11(17.2)$ & 0.774 \\
\hline Sick sinus syndrome & $2(2.6)$ & 0 & $2(3.1)$ & NA \\
\hline High-degree or complete AV block & $4(5.1)$ & $2(14.3)$ & $2(3.1)$ & 0.086 \\
\hline Right bundle branch block & $17(21.8)$ & $2(14.3)$ & $15(23.4)$ & 0.452 \\
\hline Left bundle branch block & $8(10.3)$ & $1(7.6)$ & $7(10.9)$ & 0.672 \\
\hline \multicolumn{5}{|l|}{ Echocardiographic findings } \\
\hline LVEDD $(\mathrm{mm})$ & $46.0 \pm 6.1$ & $42.0 \pm 3.3$ & $46.8 \pm 6.2$ & 0.006 \\
\hline LVESD (mm & $34.4 \pm 7.1$ & $28.8 \pm 3.3$ & $35.6 \pm 7.2$ & $<0.001$ \\
\hline IVS thickness (mm) & $14.0[12.9-15.0]$ & $12.9[12.0-14.4]$ & $14.2[13.4-15.2]$ & 0.081 \\
\hline PW thickness (mm) & $13.3[12.6-14.8]$ & $12.7[11.8-14.2]$ & $13.6[13.0-15.1]$ & 0.035 \\
\hline IVS thickness $<12 \mathrm{~mm}$ & $8(10.3)$ & $4(28.5)$ & $4(6.3)$ & 0.013 \\
\hline $\operatorname{LVEF}(\%)$ & $50.6 \pm 11.9$ & $58.4 \pm 8.9$ & $48.9 \pm 11.8$ & 0.006 \\
\hline LVEF $\geq 50 \%$ & $51(65.3)$ & $12(85.7)$ & $39(61.0)$ & 0.025 \\
\hline Stroke volume index $\left(\mathrm{mL} / \mathrm{m}^{2}\right)$ & $33.3 \pm 9.4$ & $36.6 \pm 6.5$ & $32.5 \pm 9.7$ & 0.144 \\
\hline LV mass index $\left(\mathrm{g} / \mathrm{m}^{2}\right)$ & $158.1 \pm 36.8$ & $146.5 \pm 30.8$ & $160.8 \pm 37.8$ & 0.193 \\
\hline Relative wall thickness & $0.60 \pm 0.11$ & $0.62 \pm 0.09$ & $0.59 \pm 0.12$ & 0.294 \\
\hline Left atrium diameter (mm) & $47.4 \pm 6.9$ & $44.5 \pm 5.2$ & $48.0 \pm 7.1$ & 0.087 \\
\hline Left atrium volume index $\left(\mathrm{mL} / \mathrm{m}^{2}\right)$ & $65.1 \pm 40.0$ & $56.9 \pm 21.3$ & $67.2 \pm 43.1$ & 0.355 \\
\hline E/A ratio & $1.85[0.98-2.73]$ & $1.24[1.07-1.79]$ & $2.24[0.96-2.77]$ & 0.407 \\
\hline \multicolumn{5}{|l|}{ E/e' ratio } \\
\hline Septal & $23.2 \pm 8.2$ & $24.4 \pm 7.6$ & $22.9 \pm 8.4$ & 0.545 \\
\hline Lateral & $15.8 \pm 5.5$ & $16.8 \pm 4.8$ & $15.6 \pm 5.7$ & 0.495 \\
\hline
\end{tabular}

Unless indicated otherwise, data are shown as mean $\pm \mathrm{SD}$, the median [interquartile range], or as $\mathrm{n}(\%)$. ATTRwt, wild-type transthyretin amyloidosis; AV, atrioventricular; ECG, electrocardiogram; IVS, interventricular septum; LV, left ventricular; LVEDD, LV end-diastolic diameter; LVEF, LV ejection fraction; LVESD, LV end-systolic diameter; NA, not available; PW, posterior wall. 
Table 3. Proportion of Biopsies Positive for Transthyretin Amyloid Deposits in Various Tissues

\begin{tabular}{lcccc} 
& $\begin{array}{c}\text { All patients } \\
(\mathbf{n = 7 8 )}\end{array}$ & $\begin{array}{c}\text { Females } \\
(\mathbf{n = 1 4 )}\end{array}$ & $\begin{array}{c}\text { Males } \\
(\mathbf{n = 6 4 )}\end{array}$ & P value \\
Skin & $5 / 61(8.2)$ & $1 / 10(10.0)$ & $4 / 51(7.9)$ & 0.890 \\
Abdominal subcutaneous fatty tissue & $21 / 59(35.6)$ & $8 / 10(80.0)$ & $13 / 49(26.5)$ & 0.016 \\
Stomach or jejunal mucosa & $5 / 19(26.3)$ & $1 / 2(50.0)$ & $4 / 17(23.5)$ & 0.421 \\
Heart & $35 / 35(100)$ & $3 / 3(100)$ & $32 / 32(100)$ & 1 \\
\hline
\end{tabular}

Data show the number of positive biopsies/the number of total biopsies, with percentages in parentheses.

\section{Table 4. Prevalence of ATTRwt by Sex in the Present Study and in Previous Published Series}

\begin{tabular}{|c|c|c|c|c|}
\hline $\begin{array}{l}\text { Study } \\
\text { (year of publication) }\end{array}$ & Institution, location & ATTRwt patients & $\begin{array}{l}\text { Age at } \\
\text { diagnosis } \\
\text { (years) }\end{array}$ & $\begin{array}{l}\text { ATTRwt } \\
\text { prevalence } \\
\text { by sex }\end{array}$ \\
\hline \multicolumn{5}{|c|}{ Case series study for patients diagnosed with ATTRwt } \\
\hline Present study & $\begin{array}{l}\text { Kochi Medical School Hospital, Kochi, } \\
\text { Japan }\end{array}$ & $\begin{array}{l}78 \text { patients with biopsy-confirmed ATTRwt and/ } \\
\text { or positive uptake on } 99 \mathrm{mTC} \text {-PYP scintigraphy }\end{array}$ & $81.3 \pm 5.2$ & $82 \%$ male \\
\hline $\begin{array}{l}\text { Pinney et al8 } \\
\text { (2013) }\end{array}$ & $\begin{array}{l}\text { UK National Amyloidosis Centre, } \\
\text { London, UK }\end{array}$ & 99 patients with biopsy-confirmed ATTRwt & 73.0 & $89 \%$ male \\
\hline $\begin{array}{l}\text { Grogan et al9 } \\
(2016)\end{array}$ & Mayo Clinic, Rochester, MN, USA & 360 patients with biopsy-confirmed ATTRwt & 75.5 & $91 \%$ male \\
\hline $\begin{array}{l}\text { Connors et al } \\
(2016)\end{array}$ & $\begin{array}{l}\text { Boston University Amyloidosis } \\
\text { center, Boston, MA, USA }\end{array}$ & 121 patients with biopsy-confirmed ATTRwt & 75.1 & $98 \%$ male \\
\hline $\begin{array}{l}\text { González-López } \\
\text { et al11 }(2017)\end{array}$ & $\begin{array}{l}\text { Hospital Universitario Puerta de Hierro } \\
\text { Majadahonda, Madrid, Spain, and } \\
\text { University of Bologna, Bologna, Italy }\end{array}$ & $\begin{array}{l}108 \text { patients with biopsy-confirmed ATTRwt or } \\
\text { positive uptake on } 99 \mathrm{mTC} \text {-DPD scintigraphy }\end{array}$ & $78.6 \pm 8.0$ & $81 \%$ male \\
\hline Siepen et al10 & University of Heidelberg, Heidelberg, & 191 patients with biopsy-confirmed ATTRwt & $73.8 \pm 0.5$ & $92 \%$ male \\
\hline
\end{tabular}

(2018) Germany

ATTRwt

\section{Screening studies for subjects without a prior diagnosis of ATTRwt}

\begin{tabular}{|c|c|c|c|c|}
\hline $\begin{array}{l}\text { Tanskanen et al } 24 \\
(2008)\end{array}$ & University of Helsinki, Helsinki, Finland & $\begin{array}{l}64 \text { patients with post-mortem diagnosis of } \\
\text { ATTRwt among } 256 \text { patients in a } \\
\text { population-based autopsy study }\end{array}$ & $93.8 \pm 4.3$ & $\begin{array}{r}\text { Males, } 34 \% \text {; } \\
\text { females, } 23 \%\end{array}$ \\
\hline $\begin{array}{l}\text { Mohammed et al25 } \\
(2014)\end{array}$ & Mayo Clinic, Rochester, MN, USA & $\begin{array}{l}18 \text { patients with post-mortem diagnosis of } \\
\text { ATTRwt among } 109 \text { patients with antemortem } \\
\text { diagnosis of HF with an LVEF }>40 \%\end{array}$ & $89.0 \pm 8.0$ & $\begin{array}{r}\text { Males, } 19 \% \\
\text { females, } 15 \%\end{array}$ \\
\hline $\begin{array}{l}\text { González-López } \\
\text { et al }{ }^{4}(2015)\end{array}$ & $\begin{array}{l}\text { Hospital Universitario Puerta de Hierro } \\
\text { Majadahonda, Madrid, Spain }\end{array}$ & $\begin{array}{l}16 \text { patients with positive uptake on } 99 \mathrm{mTc}-\mathrm{DPD} \\
\text { scintigraphy among } 120 \text { patients admitted due } \\
\text { to HFpEF with LV hypertrophy ( } \geq 12 \mathrm{~mm})\end{array}$ & $86.0 \pm 6.0$ & $\begin{array}{l}\text { Males, } 16 \% \text {; } \\
\text { females, } 11 \%\end{array}$ \\
\hline $\begin{array}{l}\text { Scully et al }{ }^{26} \\
(2018)\end{array}$ & Queen Mary University, London, UK & $\begin{array}{l}14 \text { patients with positive uptake on } 99 \mathrm{mTc}-\mathrm{DPD} \\
\text { scintigraphy among } 101 \text { patients referred for } \\
\text { TAVR for aortic valve stenosis }\end{array}$ & $88.0 \pm 6.0$ & $\begin{array}{r}\text { Males, } 16 \% \text {; } \\
\text { females, } 12 \%\end{array}$ \\
\hline $\begin{array}{l}\text { Tsutsui et al27 } \\
(2019)\end{array}$ & $\begin{array}{l}\text { Saiseikai Fukuoka General Hospital, } \\
\text { Fukuoka, Japan }\end{array}$ & $\begin{array}{l}18 \text { patients with positive uptake of } 99 \mathrm{mTC}-\mathrm{PYP} \\
\text { scintigraphy among } 98 \text { patients with heart } \\
\text { failure screened for ATTR }\end{array}$ & $82.3 \pm 11.7$ & $\begin{array}{r}\text { Males, } 21 \% \text {; } \\
\text { females, } 14 \%\end{array}$ \\
\hline
\end{tabular}

Data are shown as mean $\pm \mathrm{SD}$, median or $\mathrm{n}(\%)$. ATTRwt, wild-type transthyretin amyloidosis; ATTR, transthyretin amyloidosis; DPD, 3,3-diphosphono-1,2-propanodicarboxylic acid; HF, heart failure; HFpEF, HF with preserved ejection fraction; LV, left ventricle; LVEF, LV ejection fraction; PYP, pyrophosphate; TAVR, transcatheter aortic valve replacement; $99 \mathrm{mTc}$, technetium- $99 \mathrm{~m}$.

study cohort at the time of diagnosis stratified by sex. Female patients tended to be older than male patients at the onset of cardiac symptoms and had a smaller BSA than male patients. There were no significant differences between female and male patients in HF stage, NYHA functional class, the prevalence of cardiovascular comorbidities, carpal tunnel syndrome, and lumber canal stenosis, values of cardiac biomarkers and the prevalence of positive cardiac uptake on ${ }^{99} \mathrm{~m}$ Tc-PYP scintigraphy. Most patients had Subtype C or D HF at the time of diagnosis. Plasma BNP and serum hs-cTnT concentrations were significantly elevated in both female and male patients. All patients had hs-cTnT concentrations $>0.014 \mathrm{ng} / \mathrm{mL}$ (where
$0.014 \mathrm{ng} / \mathrm{mL}$ is considered normal in healthy adults ${ }^{21}$, with concentrations ranging from 0.018 to $0.232 \mathrm{ng} / \mathrm{mL}$.

\section{ECG and Echocardiographic Parameters According to Sex}

Table 2 shows ECG and echocardiographic characteristics. Atrial fibrillation was the most frequent abnormal ECG finding (in $>50 \%$ of patients) in both female and male patients. LV size was smaller and LVEF was higher $(58.4 \pm 8.9 \%$ vs. $48.9 \pm 11.8 \% ; \mathrm{P}=0.006)$ in female than male patients, and the frequency of HF with preserved LVEF ( $\mathrm{HFpEF}$; EF $>50 \%$ ) at the time of diagnosis was higher among female than male patients $(85.7 \%$ vs. $61.0 \%$, respectively; $\mathrm{P}=0.025)$. Female patients had a smaller $\mathrm{LV}$ wall 
thickness (IVS thickness: 12.9 vs. $14.2 \mathrm{~mm}[\mathrm{P}=0.081]$; PW thickness: 12.7 vs. $13.6 \mathrm{~mm}[\mathrm{P}=0.035])$ than male patients. The lack of significant LVH (IVS thickness $<12 \mathrm{~mm}$ ) at the time of diagnosis was more frequent in female than patients $(28.5 \%$ vs. $6.3 \%$, respectively; $\mathrm{P}=0.013)$. Conversely, there were no significant differences between female and male patients in SVI, LVMI, RWT, and LAVI. SVI was almost equal to the proposed SVI threshold of $35 \mathrm{~mL} / \mathrm{m}^{2}$ as a low-flow state or normal-flow state ${ }^{22,23}$ in both female and male patients.

LVMI and RWT were increased and LAVI was above the normal range in both female and male patients.

\section{Results of Organ Biopsies According to Sex}

The results of organ biopsies are presented in Table 3. Skin, abdominal subcutaneous fatty tissue, and the upper gastrointestinal tract were common sites for non-cardiac tissue sampling. The rate of TTR detection in abdominal fat tissue was significantly higher in female than male patients. Conversely, all patients, both female and male, in whom EMB was performed were positive for amyloid.

\section{Discussion}

In this study, although the number of patients was relatively small, $18 \%$ of patients diagnosed with ATTRwt were female, and the male preponderance was lower than in previous studies. ${ }^{2,8-10}$ Female ATTRwt patients had a higher sensitivity for TTR detection in abdominal fat tissue, smaller LV cavity, milder LVH, and a higher frequency of preserved LVEF than male ATTRwt patients.

There have been few studies in which sex differences in ATTRwt have been investigated, ${ }^{\mathbf{1 1}, 13,14}$ and information on Japanese female patients with ATTRwt remains insufficient. Below, we discuss the clinical features of ATTRwt in female patients.

\section{Frequency of ATTRwt in Females}

The actual overall prevalence and sex-specific characteristics of ATTRwt are unknown because population-based surveillance has never been performed. The proportion of males among patients with ATTRwt in our study and in previous published series is presented in Table 4. Some large series reported a strong male predominance in ATTRwt 2,8-10 (Table 4). Conversely, a higher age at diagnosis and a relatively lower predominance of male patients were found in the present study and in a Spanish and Italian cohort study by González-López et a ${ }^{11}$ compared with other series. These differences in clinical features may have resulted from a bias in patient cohorts from referral tertiary centers or community-based medical facilities. Furthermore, non-invasive diagnostic modalities, including $99 \mathrm{~m} T \mathrm{~T}-$-labelled scintigraphy, were used for some patients in the present study and in the Spanish and Italian cohort study. ${ }^{11}$ This approach may have increased the rate of diagnosis of female ATTR wt patients, particularly among elderly female patients with mild LVH.

Even more interestingly, several screening studies for subjects without a prior diagnosis of ATTRwt (Table 4) found a higher age at diagnosis and no strong male predominance. ${ }^{4,24-27}$ These results suggest that ATTRwt may be more common in females and in the elderly population and that it may have been largely underdiagnosed in daily clinical practice.

\section{Clinical Characteristics of Female ATTRwt Patients}

We focused on cardiac structure or function according to sex, and identified some trends in our cohort as also reported in a previous review of ATTR-CA, ${ }^{14}$ specifically lower LV wall thickness, smaller LV size, and higher LVEF in female than male patients. Furthermore, the severity of HF (HF stage, NYHA functional class, and plasma BNP concentration) did not different between female and male patients in our cohort. LVMI and RWT were increased, LAVI was greater, and the SVI tended to be reduced in both female and male patients. According to LVMI and RWT values, almost all our patients, both female and male, were categorized as having concentric LV hypertrophy with geometric patterns.

A previous study showed that despite $\mathrm{EF}$ often being initially normal in CA, the actual physiologic performance of the LV is not intact because of amyloid-associated changes in ventricular remodeling, reduced chamber capacitance, and decreased chamber contractility. ${ }^{28}$ In addition, in patients with HFpEF, so-called diastolic HF, some studies have suggested that a low-flow phenotype $\left(\mathrm{SVI}<35 \mathrm{~mL} / \mathrm{m}^{2}\right)$ in HFpEF was independently associated with low exercise capacity, poor quality of life, and a high risk of HF hospitalization. ${ }^{29,30}$ Our Japanese female elderly patients had a small BSA, and so concentric LV hypertrophy and a low-flow state may easily appear. Consequently, Japanese female ATTR wt patients may be more symptomatic under conditions of HFpEF even before the advanced phase of ATTRwt, with reduced LVEF and moderately increased LV wall thickness.

Thus, clinicians should be aware of the possibility of ATTRwt in female patients with a low threshold even if they are at the stage of preserved EF and mild LV hypertrophy. The use of lower cut-off values or cardiac dimensions indexed by BSA to diagnose ATTR-CA in females has been discussed ${ }^{14}$ because females are less likely to meet the diagnostic wall thickness threshold.

The mechanism responsible for the disparities in the prevalence and onset of cardiomyopathy between male and female ATTRwt patients remains to be clarified and the reasons for sex differences in ATTR fibril formation are also unknown. A few reports suggest that the cardioprotective effects of estrogen may be related to the low frequency and late onset of ATTRwt in females. ${ }^{31,32}$ Additional studies into the detailed clinical characteristics of ATTRwt in females and the mechanism underlying the sex differences are needed.

\section{Abdominal Fat Pad Biopsy: Potential Diagnostic Utility in Female ATTRwt Patients}

Regarding the biopsy site, a recent study on ATTRv-CA showed that female patients had a higher sensitivity to TTR deposition from abdominal fat than male patients. ${ }^{33}$ Based on results of previous studies showing that male patients were more prone to cardiac ATTR deposition than female patients, ${ }^{32,34,35}$ it was speculated that females may develop cardiomyopathy at later stages of the disease, thus allowing for more amyloid accumulation in non-cardiac tissues. It has not been determined whether this rule applies to patients with ATTRwt. However, $80 \%$ of female patients in our cohort in whom an abdominal fat pad biopsy was performed were positive for amyloid. Abdominal fat biopsy is clearly less invasive than EMB, and we therefore suggest that abdominal fat biopsy should be performed particularly in elderly female patients with sus- 


\section{pected ATTRwt.}

\section{Study Limitations}

One limitation of the present study is its single-center design and relatively small number of patients. A centerspecific bias and limited data may have affected some of the statistical analyses. More data from larger groups are needed to validate our results. Second, there was a lack of information about prognosis because the number of mortality events was limited in female ATTRwt patients. During the follow-up period (median 1.54 years; IQR 1.04-2.88 years), $4(28.6 \%)$ of the 14 female ATTRwt patients died. Further studies on sex-related differences in the clinical course in patients with ATTRwt are needed to provide important information for management and decisions regarding treatment strategies.

As a further limitation of this retrospective study, in the diagnostic work-up of patients with HF, each physician decided whether to perform ${ }^{99 \mathrm{~m} T c-P Y P}$ scintigraphy in patients with HF. This may have affected some of the results.

\section{Conclusions}

There was a considerably large number of females with ATTRwt in our Japanese cohort. Female ATTRwt patients had HF symptoms at the stage of preserved EF and mild LV hypertrophy accompanied by low cardiac output. We should be aware of the possibility of ATTRwt in elderly female patients with HF, particularly in patients with HFpEF. For elderly female patients with mild LV hypertrophy, abdominal fat pad biopsy may have a high potential to identify ATTRwt.

\section{Sources of Funding}

This work was supported in part by a research grant from the Japan Society for the Promotion of Science (18k08078; to H.K.).

\section{Disclosures}

T.K. and H.K. have received consulting fees or honoraria and remuneration for lectures from Pfizer Japan Inc.

H.K. is a member of Circulation Reports' Editorial Team. The remaining authors have no conflicts of interest to declare.

\section{IRB Information}

This study was approved by the Ethics Committee on Medical Research of Kochi Medical School (Reference no. ERB-002080).

\section{References}

1. Liu PP, Smyth D. Wild-type transthyretin amyloid cardiomyopathy: A missed cause of heart failure with preserved ejection fraction with evolving treatment implications. Circulation 2016; 133: $245-247$.

2. Connors LH, Sam F, Skinner M, Salinaro F, Sun F, Ruberg FL, et al. Heart failure resulting from age-related cardiac amyloid disease associated with wild-type transthyretin: A prospective, observational cohort study. Circulation 2016; 133: 282-290.

3. Mohammed SF, Mirzoyev SA, Edwards WD, Dogan A, Grogan DR, Dunlay SM, et al. Left ventricular amyloid deposition in patients with heart failure and preserved ejection fraction. JACC Heart Fail 2014; 2: 113-122.

4. Gonzalez-Lopez E, Gallego-Delgado M, Guzzo-Merello G, de Haro-Del Moral FJ, Cobo-Marcos M, Robles C, et al. Wild-type transthyretin amyloidosis as a cause of heart failure with preserved ejection fraction. Eur Heart J 2015; 36: 2585-2594.

5. Maurer MS, Schwartz JH, Gundapaneni B, Elliott PM, Merlini $\mathrm{G}$, Waddington-Cruz M, et al. Tafamidis treatment for patients with transthyretin amyloid cardiomyopathy. N Engl J Med 2018; 379: $1007-1016$
6. Endo J, Sano M, Izumiya Y, Tsujita K, Nakamura K, Tahara $\mathrm{N}$, et al. A statement on the appropriate administration of tafamidis in patients with transthyretin cardiac amyloidosis. Circ J 2019; 84: 15-17.

7. Kitaoka H, Izumi C, Izumiya $\mathrm{Y}$, Inomata $\mathrm{T}$, Ueda $\mathrm{M}$, Kubo $\mathrm{T}$, et al; on behalf of the Japanese Circulation Society Joint Working Group. JCS 2020 guideline on diagnosis and treatment of cardiac amyloidosis. Circ J 2020; 84: 1610-1671.

8. Pinney JH, Whelan CJ, Petrie A, Dungu J, Banypersad SM, Sattianayagam P, et al. Senile systemic amyloidosis: Clinical features at presentation and outcome. Am Heart Assoc 2013; 2: e000098.

9. Grogan M, Scott CG, Kyle RA, Zeldenrust SR, Gertz MA, Lin $\mathrm{G}$, et al. Natural history of wild-type transthyretin cardiac amyloidosis and risk stratification using a novel staging system. $J$ Am Coll Cardiol 2016; 68: 1014-1020.

10. Siepen FAD, Bauer R, Voss A, Hein S, Aurich M, Riffel J, et al. Predictors of survival stratification in patients with wild-type cardiac amyloidosis. Clin Res Cardiol 2018; 107: 158-169.

11. González-López E, Gagliardi C, Dominguez F, Quarta CC, de Haro-Del Moral FJ, Milandri A, et al. Clinical characteristics of wild-type transthyretin cardiac amyloidosis: Disproving myths. Eur Heart J 2017; 38: 1895-1904.

12. Ochi Y, Kubo T, Nakashima Y, Baba Y, Hirota T, Yamasaki N, et al. Integrated diagnostic approach to wild-type transthyretin cardiac amyloidosis with the use of high-sensitivity cardiac troponin T measurement and ${ }^{99} \mathrm{~m}$ Tc-pyrophosphate scintigraphy. $J$ Cardiol 2020; 75: 12-19.

13. Kristen AV, Bauer R, Siepen F, Kimmich C, Hinderhofer K, Röcken C, et al. Wild-type transthyretin amyloidosis in female patients. Orphanet J Rare Dis 2015; 10(Suppl 1): O9.

14. Bruno M, Castaño A, Burton A, Grodin JL. Transthyretin amyloid cardiomyopathy in women: Frequency, characteristics, and diagnostic challenges. Heart Fail Rev 2021; 26: 35-45.

15. Gertz MA, Comenzo R, Falk RH, Fermand JP, Hazenberg BP, Hawkins PN, et al. Definition of organ involvement and treatment response in immunoglobulin light chain amyloidosis (AL): A consensus opinion from the 10th International Symposium on Amyloid and Amyloidosis, Tours, France, 18-22 April 2004. Am J Hematol 2005; 79: 319-328.

16. Castaño A, Haq M, Narotsky DL, Goldsmith J, Weinberg RL, Morgenstern R, et al. Multicenter study of planar technetium $99 \mathrm{~m}$ pyrophosphate cardiac imaging: Predicting survival for patients with ATTR cardiac amyloidosis. JAMA Cardiol 2016; 1: $880-889$.

17. Perugini E, Guidalotti PL, Salvi F, Cooke RM, Pettinato C, Riva L, et al. Noninvasive etiologic diagnosis of cardiac amyloidosis using $99 \mathrm{~m} \mathrm{Tc}-3,3$-diphosphono-1,2-propanodicarboxylic acid scintigraphy. J Am Coll Cardiol 2005; 46: 1076-1084.

18. Yancy CW, Jessup M, Bozkurt B, Butler J, Casey DE Jr, Drazner MH, et al. 2013 ACCF/AHA guideline for the management of heart failure: A report of the American College of Cardiology Foundation/American Heart Association Task Force on practice guidelines. Circulation 2013; 128: e240-e327.

19. DePace NL, Colby J, Hakki AH, Manno B, Horowitz LN, Iskandrian AS. Poor R wave progression in the precordial leads: Clinical implications for the diagnosis of myocardial infarction. Am Coll Cardiol 1983; 2: 1073-1079.

20. Lang RM, Badano LP, Mor-Avi V, Afilalo J, Armstrong A, Ernande L, et al. Recommendations for cardiac chamber quantification by echocardiography in adults: An update from the American Society of Echocardiography and the European Association of Cardiovascular Imaging. Eur Heart J Cardiovasc Imaging 2015; 16: 233-270.

21. Saenger AK, Beyrau R, Braun S, Cooray R, Dolci A, Freidank $\mathrm{H}$, et al. Multicenter analytical evaluation of a high-sensitivity troponin T assay. Clin Chim Acta 2011; 412: 748-754.

22. Hachicha Z, Dumesnil JG, Bogaty P, Pibarot P. Paradoxical low-flow, low-gradient severe aortic stenosis despite preserved ejection fraction is associated with higher afterload and reduced survival. Circulation 2007; 115: 2856-2864.

23. Nishimura RA, Otto CM, Bonow RO, Carabello BA, Erwin JP 3rd, Guyton RA, et al. 2014 AHA/ACC guideline for the management of patients with valvular heart disease: Executive summary: A report of the American College of Cardiology/American Heart Association Task Force on Practice Guidelines. Circulation 2014; 129: 2440-2492.

24. Tanskanen M, Peuralinna T, Polvikoski T, Notkola IL, Sulkava $\mathrm{R}$, Hardy J, et al. Senile systemic amyloidosis affects $25 \%$ of the very aged and associates with genetic variation in alpha2-macro- 
globulin and tau: A population-based autopsy study. Ann Med 2008; 40: 232-239.

25. Mohammed SF, Mirzoyev SA, Edwards WD, Dogan A, Grogan DR, Dunlay SM, et al. Left ventricular amyloid deposition in patients with heart failure and preserved ejection fraction. $J A C C$ Heart Fail 2014; 2: 113-122.

26. Scully PR, Treibel TA, Fontana M, Lloyd G, Mullen M, Pugliese $\mathrm{F}$, et al. Prevalence of cardiac amyloidosis in patients referred for transcatheter aortic valve replacement. J Am Coll Cardiol 2018; 71: $463-464$.

27. Tsutsui Y, Kubota T, Kato S, Nozoe M, Suematsu N, Okabe M, et al. Utility of ${ }^{99 \mathrm{~m}} \mathrm{Tc}$-pyrophosphate scintigraphy in diagnosing transthyretin cardiac amyloidosis in real-world practice. Circ Rep 2019; 1: 277-285.

28. Bhuiyan T, Helmke S, Patel AR, Ruberg FL, Packman J, Cheung K, et al. Pressure-volume relationships in patients with transthyretin (ATTR) cardiac amyloidosis secondary to V122I mutations and wild-type transthyretin: Transthyretin Cardiac Amyloid Study (TRACS). Circ Heart Fail 2011; 4: 121-128.

29. Patel KV, Mauricio R, Grodin JL, Ayers C, Fonarow GC, Berry JD, et al. Identifying a low-flow phenotype in heart failure with preserved ejection fraction: A secondary analysis of the RELAX trial. ESC Heart Fail 2019; 6: 613-620.
30. Guazzi M, Adams V, Conraads V, Halle M, Mezzani A, Vanhees L, et al. EACPR/AHA scientific statement: Clinical recommendations for cardiopulmonary exercise testing data assessment in specific patient populations. Circulation 2012; 126: 2261-2274.

31. Rapezzi C, Riva L, Quarta CC, Perugini E, Salvi F, Longhi S, et al. Gender-related risk of myocardial involvement in systemic amyloidosis. Amyloid 2008; 15: 40-48.

32. Tasaki M, Ueda M, Obayashi K, Koike H, Kitagawa K, Ogi Y, et al. Effect of age and sex differences on wild-type transthyretin amyloid formation in familial amyloidotic polyneuropathy: A proteomic approach. Int J Cardiol 2013; 170: 69-74.

33. Paulsson Rokke H, Sadat Gousheh N, Westermark P, Suhr OB, Anan I, Ihse E, et al. Abdominal fat pad biopsies exhibit good diagnostic accuracy in patients with suspected transthyretin amyloidosis. Orphanet J Rare Dis 2020; 15: 278.

34. Rapezzi C, Quarta CC, Obici L, Perfetto F, Longhi S, Salvi F, et al. Disease profile and differential diagnosis of hereditary transthyretin-related amyloidosis with exclusively cardiac phenotype: An Italian perspective. Eur Heart J 2013; 34: 520-528.

35. Arvidsson S, Pilebro B, Westermark P, Lindqvist P, Suhr OB Amyloid cardiomyopathy in hereditary transthyretin V30M amyloidosis: Impact of sex and amyloid fibril composition. PLoS One 2015; 10: $\mathrm{e} 0143456$. 